\title{
A TAXA SELIC E SEU IMPACTO NA ECONOMIA BRASILEIRA
}

\section{THE SELIC RATE AND ITS IMPACT ON THE BRAZILIAN ECONOMY}

\begin{abstract}
Edmilson Rosa Bramante, Acadêmico do Curso de Administração da Faculdade Alfaunipac de Teófilo Otoni, Brasil. e-mail: bramante2010@gmail.com

Walério Júnio Lopes Rodrigues, Acadêmico do Curso de Administração da Faculdade Alfaunipac de Teófilo Otoni, Brasil. e-mail: waleriovava@hotmail.com
\end{abstract}

Danilo Carvalho Miranda, Especialista em Gestão de Negócios e Finanças, Professor Fundação Presidente Antônio Carlos de Teófilo Otoni, Brasil. e-mail: danilocarvalho.unipacto@hotmail.com

Recebido: 10/11/2020 - Aceito: 27/11/2020

\section{Resumo}

A economia brasileira conta com diversos indicadores. Entre eles a Taxa Selic, que é considerada a taxa básica da economia, já que é utilizada em operações entre bancos e tem influência sobre os juros de toda a economia brasileira. No entanto, é cada vez mais comum a autoavaliação da viabilidade de investimentos por parte de pessoas e empresas, e em contrapartida pouco se trabalha com a análise interna dos cenários econômicos. Através de pesquisa bibliográfica e diagnóstico de mercado, o estudo do tema propõe um levantamento histórico do assunto, em paralelo à sua correlação com as projeções econômicas, levantando-se surgimento, evolução e importância da Taxa Selic para a economia Brasileira. Dentro deste contexto, o artigo prima em ressaltar separadamente a correlação entre este instrumento do Comitê de Política Monetária - um órgão constituído no âmbito do Banco Central do Brasil em 20 de junho de 1996 - com as finalidades de estabelecer as diretrizes da política financeira e definir a taxa básica de juros ligada direta e indiretamente à vida dos brasileiros.

Palavras-chave: Economia; Mercado; Indicadores; Taxa Selic.

\section{Abstract}

The Brazilian economy has several indicators. Among them, the Selic Rate, which is considered the basic rate of the economy, since it is used in transactions between banks and has an influence on interest rates throughout the Brazilian economy. However, it is increasingly common to self-assess the feasibility of investments by individuals and companies, and in return little is done with the internal analysis of economic scenarios. 
Through bibliographic research and market diagnosis, the study of the theme proposes a historical survey of the subject, in parallel to its correlation with economic projections. Raising the emergence, evolution and importance of the Selic Rate for the Brazilian economy. Within this context, the article stresses separately the correlation between this instrument of the Monetary Policy Committee - an organ established within the scope of the Central Bank of Brazil on June 20, 1996 - with the purpose of establishing financial policy guidelines and defining the basic interest rate linked directly and indirectly to the lives of Brazilians.

Key words: Economy; Market; Indicators; Selic Rate.

\section{Introdução}

A ideia de economia saudável parte da capacidade das empresas em criar empregos, lucrar, e consequentemente crescer. Observa-se que no setor empresarial há vários indicadores de desempenho que constituem o conjunto de medidas para a tomada de decisão dentro das empresas. Essas métricas são usadas para determinar o progresso de uma empresa e se ela está mais próxima, ou não, de alcançar seus objetivos estratégicos e metas.

Uma importante ferramenta para medir a economia são os indicadores. Segundo a equipe do portal André Bona (2019), "indicador é uma estatística que supõe a medição de uma variável durante certo período". A utilização eficiente destes indicadores contribui para o sucesso dos negócios, visto que podem ser usados como ferramentas de estratégia em diferentes níveis de departamentos organizacionais, além de apoiar planejamento e estratégias.

Pode-se citar alguns indicadores que são grandes referências na tomada de decisão econômica brasileira: Instituto brasileiro de geografia e estatística (IBGE), Produto Interno Bruto (PIB), Taxa Selic, Balança Comercial, Índice de Desenvolvimento Humano (IDH), entre outros. Daí a indagação principal sobre qual a importância real da Taxa Selic para a economia brasileira? Já que esta vem ganhando destaque quando se fala em investimentos empresariais.

Para tanto, propõe-se levantar como objetivos da obra uma pesquisa bibliográfica retratando o surgimento, evolução e importância da Taxa Selic para a economia Brasileira, bem como suas mudanças e projeções temporais. O presente artigo também sugere um aclaramento teórico com base em pesquisas sobre investidores e os relatórios 
da taxa Selic que são divulgados todos meses. Pois é cada vez mais comum contratar analistas para estudar onde melhor investir para minimizar o risco de prejuízos; e em contrapartida pouco se trabalha com a análise interna dos cenários econômicos de um país. Como diz Duran (1992): "Gerenciar é controlar. Sem controle não há gerenciamento. Sem medição, não há controle".

\section{Revisão bibliográfica}

\subsection{A Importância de Conhecer os Indicadores Financeiros da Economia}

O século XXI faz parte da tida por muitos como "a sociedade do conhecimento", tem-se acesso à informação como nunca se teve antes e também facilidades de recursos não disponíveis outrora - como mão de obra barata, recursos de capital mais acessível, facilidades de comunicação e logística (TERRA, 2000).

De acordo com Hernandes, Cruz e Falcão (2000, p. 3) a "gestão do conhecimento é o processo pelo qual uma organização, consciente e sistematicamente, coleta, cria, organiza, compartilha e quantifica seu acervo de conhecimento para atingir seus objetivos estratégicos". Ainda segundo os autores, tem-se a necessidade deter uma visão de conhecimento e gestão bem clara antes de começa um trabalho.

Para o bom desenvolvimento e aprendizagem em grupo, é necessário que se transforme o conhecimento tácito, que nada mais é do que o conhecimento que uma pessoa adquiriu ao longo da vida, através de suas experiências, em conhecimento explícito, que é o conhecimento compartilhado, ou seja, é transmitido de maneira clara e objetiva, sem complicações, para os demais (NONAKA; TAKEUCHI, 1997).

Marion (2012) afirma que só há condições de conhecer a situação econômicofinanceira de uma empresa por meio dentre análises, sendo elas a análise de Liquidez, Rentabilidade e de Endividamento. Nestes pensamentos autores, Soares, Machado e Schumacher (2010) levantam a prerrogativa que as demonstrações e o levantamento dos resultados não são suficientes na atualidade. Diante da afirmação dos autores, a análise econômico-financeira, que costuma ser realizada a partir das demonstrações contábeis, está proporcionando dados de cunho econômico-administrativo aos seus diversos usuários, e consequentemente contribuindo para a tomada de decisões.

Para Marion (2009), os índices são relações que se estabelecem entre duas grandezas, facilitando assim sensivelmente o trabalho do analista uma vez que a análise 
de certas relações ou percentuais é mais significativa do que a observação apenas dos montantes.

Conforme o pensamento de Coronado (2006), a sobrevivência das empresas, em um ambiente competitivo, vincula-se diretamente à capacidade que os elementos têm de se antecipar aos acontecimentos desse ambiente. A administração das empresas bem sucedidas apoia-se em processos de planejamento de suas atividades. Inclusive, o autor reitera que se as empresas não tiverem uma competividade uma entre as outras, acaba que de uma forma elas não conseguem ter um resultado melhor que a outra. E que uma empresa sem planejamento inviabiliza alcançar resultados positivo, acarretando resultados negativos.

\subsection{O que é a Taxa Selic}

Segundo o Comitê de Política Monetária $\left(\right.$ Copom $\left.^{1}\right)$ o termo Selic é uma sigla, e significa Sistema Especial de Liquidação de Custódia. A autora Wolffenbüttel (2005) evidencia que é um sistema operado pelo Banco Central (BC) e que cuida exclusivamente de negociações com títulos escriturais emitidos pelo Tesouro Nacional e pelo próprio BC, ou seja, de títulos públicos federais. Ainda para Wolffenbüttel (2005), a sigla ficou conhecida por causa da Taxa Selic, que expressa diariamente a taxa de juro aplicada nas operações de financiamento por um dia, feitas pelo BC, com esses títulos públicos.

Segundo o economista Ulisses Gamboa, nem mesmo os economistas podem prever os valores da Selic, mas é possível fazer estimativas observando outros indicadores econômicos e acompanhando as declarações do Banco Central. Para, Gamboa, estar atento às mudanças de mercado não é importante apenas para os especialistas. "O empreendedor também precisa estar sempre antenado para conhecer as taxas, tendências de consumo e, principalmente, como o setor em que a sua empresa atua está se comportando".

\subsection{Histórico Econômico da Taxa Selic}

${ }^{1}$ Comitê de Política Monetária (Copom) é um órgão constituído no âmbito do Banco Central do Brasil em 20 de junho de 1996, com as finalidades de estabelecer as diretrizes da política monetária e definir a taxa básica de juros. Tem, ainda, a competência específica de regular a liquidez da economia, por meio dos instrumentos de política monetária. 
Ao longo dos tempos inúmeros foram os índices que contribuíram para o bom funcionamento econômico-social em geral. Segundo Assaf Neto (1999), as medidas de política econômica sempre tiveram a função de auxiliar o governo na gestão da economia, buscando atingir objetivos sociais e macroeconômicos essenciais, entre eles: a estabilidade de preços, distribuição de riqueza, nível de emprego adequado e crescimento econômico. No Brasil, a Taxa Selic representa grande relevância.

Para Salvalágio (2006), a Taxa Selic é considerada a taxa básica da economia, já que é utilizada em operações entre bancos, e, por isso tem influência sobre os juros de toda a economia.

Em 04 de março de 1999, o Banco Central extinguiu o sistema utilizado de bandas de juros, criado em 1996, passando assim a utilizar-se de uma única taxa para sinalizar os juros de toda a economia: a Taxa Referencial Selic. Pode-se dizer que esta se origina de taxas de juros efetivamente observadas no mercado e refletem as condições instantâneas de liquidez no mercado monetário. Estas taxas de juros não sofrem influência do risco do tomador de recursos financeiros nas operações compromissadas, já que o lastro oferecido é homogêneo (SALVALÁGIO, 2006).

Ainda para o autor Salvalágio (2006), a primeira meta para a Taxa Selic determinada pelo Banco Central em vigor no dia 05 de março foi fixada no patamar de $45 \%$ a.a., alta o suficiente, segundo os membros do Copom, para fazer frente às pressões inflacionárias, que tiveram como causa principal, a desvalorização do real ocorrida desde o dia 13 de janeiro, porém devido aos primeiros resultados favoráveis advindos das mudanças implementadas pela política monetária, a meta Selic apresentou trajetória descendente, passando de 45,00\% a.a. em 05 de março para $29,5 \%$ a.a. no dia 10 de maio de 1999 , queda de 15,5 pontos percentuais no intervalo aproximado de 65 dias.

A utilização do viés para a meta Selic foi um mecanismo largamente utilizado nos primeiros meses após a desvalorização cambial, quando o nível de incertezas era maior, exigindo uma atuação mais flexível por parte da autoridade monetária (BANCO CENTRAL DO BRASIL, 1999). 
Segundo a XP Investimentos CCTVM S.A ${ }^{2}$ (2020), a taxa Selic está intimamente ligada aos momentos econômicos do Brasil. Afinal, a meta é o parâmetro de controle do consumo e dos preços dos juros: "Inicialmente, a taxa Selic substituiu a Taxa Referencial (TR), em 1996. Naquela época, ela entrou com foco no controle da hiperinflação. Desde então, desempenha essa e outras funções em relação ao dinheiro".

Em outubro de 2016, o BC deu início a uma sequência de 12 cortes na Selic. Neste período, a taxa de juros caiu de $14,25 \%$ ao ano para $6,5 \%$ ano. De maio de 2018 até junho de 2019, a taxa foi mantida no mesmo patamar. Foram dez encontros do Copom sem mudanças na Selic. No final de julho de 2019, porém, o Copom reduziu a Selic em 0,5 pontos percentual, para $6 \%$ ao ano. Em dezembro, a taxa já estava em 4,5\% ao ano. Em fevereiro de 2020, foi reduzida novamente, desta vez para 4,25\%; em março, para 3,75\%; e em maio, para $3 \%$ e em junho chegou a 2,25\% ao ano. (Portal UOL, junho/2020).

\section{Gráfico 1: Referencial Histórico Taxa Selic 2010 a 2019}

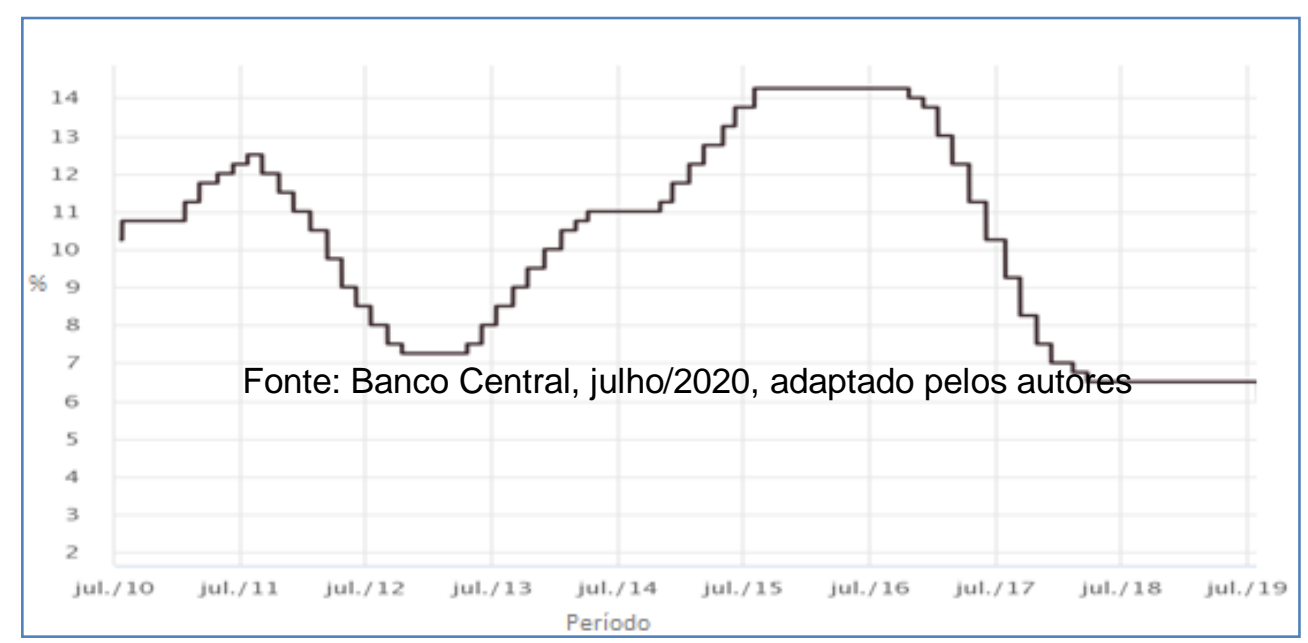

\subsection{A Influência da Taxa Selic nas Instituições Financeiras do País}

Segundo Camargo (2020), a taxa SELIC também é conhecida como "linha d'água" dos investimentos, já que a viabilidade de qualquer investimento é medida em comparação com a SELIC/CDI. Já que estes investimentos são considerados livres de risco e livres do 'trabalho' de investir, toda e qualquer aplicação deve superar o CDI no

${ }^{2}$ AXP Investimentos CCTVM S.A é instituição financeira autorizada pelo Banco Central do Brasil. Proprietária da marca Rico.com.vc, e inscrita sob o CNPJ: 02.332.886/0016-82. 
longo prazo. Enquanto a SELIC é a taxa das relações entre Governo e pessoas Físicas ou Jurídicas, O CDI é a taxa das relações entre Pessoas Físicas e Jurídicas entre si. Para o autor, o CDI está sempre muito próximo da SELIC.

A definição da Selic tem um papel estratégico no controle da inflação e na estabilização da economia brasileira. Isso porque ela representa a taxa de juros praticados, ou seja, o "preço" que se paga pelo crédito no país. Quando a Selic está alta, é mais caro emprestar dinheiro, o que diminui o capital em circulação no país e limita a inflação. Da mesma forma, se os juros estiverem muito baixos, a tendência é que os preços dos bens de consumo aumentem. Assim, o Copom usa a definição da Selic como uma maneira de controlar o excesso de dinheiro em circulação e uma possível desvalorização da moeda, guiando assim os rumos da economia. Desde 2012, o governo estabeleceu uma nova regra de cálculo que funciona da seguinte maneira:

Se a taxa Selic for maior ou igual a $8,5 \%$ ao ano, a poupança terá rendimento de $0,5 \%$ ao mês mais a TR. Quando a taxa Selic estiver abaixo de 8,5\% a.a., a poupança terá um rendimento equivalente a $70 \%$ da Selic vigente no período (XP Investimentos CCTVM S.A, 2020).

Os bancos, no intuito de sanarem furos de curtíssimo prazo em seus caixas (saques não programados maiores que as entradas), tomam recursos emprestados de outros bancos por um dia e oferecem Títulos Públicos como garantia (lastro), de forma a reduzir o risco do emprestador do recurso e consequentemente os juros da transação (CAMARGO, 2020).

\subsection{A Taxa Selic e o Consumo}

Para Coutinho (2016), a taxa Selic está também associada ao chamado custo do dinheiro. Quando ela é reduzida, o consumo da população tende a aumentar, porque o crediário se torna mais barato, e isso estimula as pessoas a comprarem mais. Com o aumento do consumo, essa demanda pode superar a oferta, e isso gera um efeito ruim chamada inflação. Para conter a inflação, um dos instrumentos utilizados é elevar a taxa básica de juros (ou taxa Selic). Com isso o custo do dinheiro fica mais alto, e crediário também, e a população começa a conter seus gastos, reduzindo a demanda. Isso provoca uma retração na economia, redução nos preços dos produtos e serviços, e tudo isso faz a inflação cair. Esta é uma explicação simplificada, é claro, pois há questões 
mais complexas envolvidas. No entanto, o importante é você ter em mente que uma taxa Selic em elevação gera retração de consumo. Taxa Selic em queda, estimula o consumo e a economia (mas pode gerar inflação).

A Selic é um mecanismo usado para controlar a inflação. Geralmente, o Copom sobe os juros da economia nas situações de inflação alta. Assim, fica mais caro obter crédito, o que ajuda a diminuir o consumo e reduzir a demanda por produtos e serviços, diminuindo a alta dos preços. Já quando a situação é de baixa atividade econômica e inflação controlada, a política adotada quase sempre é de queda dos juros. Dessa maneira, o crédito fica mais barato, facilitando investimentos por parte das empresas e consumo por parte das famílias (CONGO, 2020).

Para o professor da escola de economia da Fundação Getúlio Vargas (FGV EESP), Nelson Marconi (2020), um canal em que a Selic tem efeito rápido nos preços e cujo reflexo pode ser sentido pelos consumidores é no câmbio. Para o mestre:

Como a taxa básica de juros é usada também para indexar os títulos públicos, alterações na Selic influenciam diretamente a quantidade de investimento estrangeiro no país. Quanto maior a taxa de juros, mais estrangeiros têm interesse em investir no Brasil, o que aumenta a oferta de dólares no país. Quanto mais dólares disponíveis, por sua vez, mais barata fica a moeda norte-americana. Isso faz os produtos importados ficarem mais baratos. Por outro lado, quanto menor a taxa de juros, menor o interesse de estrangeiros em investir seus dólares no Brasil, o que diminui a quantidade de dólares e eleva a taxa de câmbio. Com isso, os preços dos produtos importados tendem a subir, aumentando também a inflação.

\subsection{Taxa Selic na Criação de Empregos}

O autor Lagullo (2020) diz que devemos pontuar que normalmente o mercado produtivo precisa de crédito para lubrificar suas engrenagens, investir e continuar fazendo a roda da economia girar e gerar riquezas para o país. Quem financia este crescimento por meio da liberação de créditos são as instituições financeiras - os bancos, que também devemos lembrar, têm como finalidade gerar lucro para seus acionistas e, por conta disto, estão atrás de oportunidade de negócios que rendam em primeiro lugar: o maior lucro possível, e em segundo: o menor risco possível. Para que uma instituição financeira ofereça crédito ao mercado, a promessa de juros tem que ser maior que a taxa paga pelo 
Governo (como no caso dos financiamentos de veículos) ou possuir um baixo risco de calote (empréstimo consignado a aposentados). Então, caso os bancos não consigam vislumbrar um destes motivos no mercado, ele optará por investir em títulos do governo, e isso trará um efeito cascata na economia que atingirá o consumidor e as empresas.

Quando uma empresa deixa de investir, automaticamente ela para de gerar emprego, o que faz com que menos pessoas tenham poder de consumo. Sem dinheiro para consumir, seu cliente não compra mais na sua empresa. Então, mesmo que seu empreendimento não precise de financiamento nem planeje comprar títulos do governo, sua loja poderá se esvaziar simplesmente porque a taxa SELIC tornou-se mais atrativa para os bancos investirem seu dinheiro no governo do que no mercado produtivo. Por isso os setores produtivos defendem uma diminuição da taxa SELIC para que os títulos do governo se tornem menos atrativos, obrigando os bancos a investirem mais nos setores produtivos. Isso faz com que a circulação de dinheiro aumente e as pessoas consumam mais. O COPOM defende que a diminuição agressiva da SELIC poderá trazer para o país o pesadelo da inflação (LAGULLO, 2020).

Segundo Silva (2016), a taxa Selic sempre será utilizada pelo governo para combater a inflação, outrossim, uma queda da taxa Selic tende a gerar um aumento no índice do preço dos produtos aumentando assim a inflação.

Quando nos deparamos com empresas que estão demitindo em massa e férias temporárias isso é sinal de que o mercado está desaquecido. $E$ isso é muito comum no mercado automobilístico devido ao baixo consumo. O aumento da taxa Selic diminui o consumo e por sua vez diminuem a quantidade de vendas realizadas pela empresa e com o número de vendas em baixa existe uma necessidade cada vez menor de colaboradores trabalhando em sua linha de produção ou na venda direta com o cliente, provocando grandes demissões (SILVA, 2016).

E assim, Lagullo (2020) afirma que a SELIC influencia a vida de qualquer empresa e pessoa que viva no Brasil, seja de forma direta ou indireta. "Por conta deste fator macroeconômico, em que a empresa não possui nenhuma influência, é extremamente importante que sua empresa tenha conhecimento sobre a sua situação financeira atual e futura para poder se adaptar o mais rápido possível as mudanças do ambiente econômico".

\section{Metodologia}


A fim de explorar o tema nas suas mais distantes nuances investigativas, o método pesquisa bibliográfica propõe a abordagem mais sistemática do tema. "Primeiramente, há que se considerar que os documentos constituem fonte rica e estável de dados. Como os documentos subsistem ao longo do tempo, tornam-se a mais importante fonte de dados em qualquer pesquisa de natureza histórica" (GIL, 2002, p.46).

Ainda para Gil (2002), inúmeras são as colaborações da pesquisa bibliográfica para pesquisador e pesquisado:

[...] a principal vantagem da pesquisa bibliográfica reside no fato de permitir ao investigador a cobertura de uma gama de fenômenos muito mais ampla do que aquela que poderia pesquisar diretamente. Essa vantagem torna-se particularmente importante quando o problema de pesquisa requer dados muito dispersos pelo espaço. Por exemplo, seria impossível a um pesquisador percorrer todo o território brasileiro em busca de dados sobre população ou renda per capita; todavia, se tem a sua disposição uma bibliografia adequada, não tem maiores obstáculos para contar com as informações requeridas. A pesquisa bibliográfica também é indispensável nos estudos históricos. Em muitas situações, não há outra maneira de conhecer os fatos passados se não com base em dados bibliográficos.(GIL, 2002, p. 3).

\section{Considerações Finais}

Este estudo teve como objetivo final elaborar e explicar sob pesquisa bibliográfica e de mercado o surgimento, evolução e importância da Taxa Selic, de como é seu comportamento na economia Brasileira e se há vantagem da Taxa Selic em relação a outros indicadores.

Desde 1999 a Selic é considerada a taxa básica porque é usada em operações entre bancos e, por isso, tem influencia sobre os juros de toda a economia. Na década de 70, a custódia dos títulos públicos no Brasil ainda era feita por processo manual, o que incluía desde o arquivamento por instituição até a movimentação física nos cofres dos bancos, com grande risco de fraude e de extravio dos papéis. Como Selic, títulos e cheques foram substituídos por simples registros eletrônicos, gerando ganhos em eficiência e agilidade, já que as operações são fechadas no mesmo dia em que se realizam. Além disso, o sistema passou a garantir que, em caso de inadimplência de qualquer das partes, a operação não se concretize. Hoje, esse sistema movimenta diariamente mais de $\mathrm{R} \$ 100$ bilhões e é fundamental para a sociedade brasileira.

A Taxa Selic é considerada o termômetro da economia, ela induz o consumo e consequentemente a criação de empregos e renda da população. Quando o governo 
diminui a Selic, as taxas cobradas pelos bancos nos empréstimos e as taxas pagas como remuneração dos investimentos também diminuem. Se a intenção do governo é movimentar a economia e incentivar o consumo, ele reduz o valor da taxa Selic. Por outro lado, se a inflação aumenta e começa a incomodar, o governo faz com que a meta da Selic diminua, para que a economia esfrie e cesse o aumento dos preços. Quando a taxa Selic aumenta e freia o consumo, as empresas vendem menos. Com isso, acabam demitindo funcionários para compensar a queda nas vendas. Da mesma forma, com a Selic mais baixa e o consumo crescendo, em tese as empresas acabam contratando mais funcionários para dar conta da demanda.

Com base na trajetória do diferencial Taxa Selic, verificou-se através das medidas observadas que a queda gradual dos títulos prefixados deu início a uma sequência de 12 cortes no ano de 2016. A partir deste período, taxa de juros caiu de $14,25 \%$ ao ano para 6,5\% ano. De maio de 2018 até junho de 2019, a taxa foi mantida no mesmo patamar. Foram dez encontros do Copom sem mudanças na Selic. No final de julho de 2019, porém, o Copom reduziu a Selic em 0,5 pontos percentual, para $6 \%$ ao ano. Em dezembro, a taxa já estava em 4,5\% ao ano. Em fevereiro de 2020, foi reduzida novamente, desta vez para 4,25\%; em março, para 3,75\%; e em maio, para $3 \%$ e em junho chegou a 2,25\% ao ano (Portal UOL, 2020). Sendo assim, vale salientar que apesar das iniciativas de redução governamentais, sabe-se que a Taxa Selic não representa exatamente os juros postos aplicados aos consumidores, que por hora são muito mais elevados.

Mesmo assim, o Banco Central diz que o sistema Selic tem um papel fundamental na instabilidade financeira, principalmente em possíveis casos de falência ou insolvência das instituições. Sua atuação monetária entrou cada vez mais em evidência, e, a taxa de juros, instrumento mais utilizado como resposta do Bacen as pressões inflacionárias, adquiriram cada vez mais notoriedade, uma vez que ela é extraída de um ambiente de negociação mais estável, onde o governo é menos exposto às turbulências da iniciativa privada. A liquidação em tempo real e o registro das transações com títulos públicos federais em seu banco de dados podem coibir fraudes e prevenir o contágio em outras instituições.

Para o gestor moderno, seja do serviço público ou privado, cabe valer-se de tais indicadores, pois quão maior for sua capacidade de agir e reagir às variáveis econômicas, tão grande será seu direcionamento ao sucesso. 


\section{Referências}

ASSAF NETO, Alexandre. Mercado Financeiro. 2. ed. São Paulo, 1999. 319 p.

BANCO CENTRAL DO BRASIL. Taxa Selic - Sistema Especial de Liquidação e Custódia. http://www.bcb.gov.br. Acesso em setembro de 2020.

Banco central no Brasil', XXXIV Encontro Nacional de Economia. Disponível em: https://acsp.org.br/publicacao/s/selic-o-que-e-e-como-afeta-a-sua-empresa. Acesso em junho de 2020.

CAMARGO, Jonathan. Taxa SELIC - Guia Definitivo sobre Taxa de Juros Brasileira. Junho/2017. Disponível em: https://londoncapital.com.br/taxa-selic. Acesso em outubro de 2020.

GIL, A. C. Como elaborar projetos de pesquisa. São Paulo: Atlas, 2002.

CONGO, Mariana. Taxa selic: o que é? Como ela afeta os investimentos? Tudo que você precisa saber. Disponível em: https://blog.magnetis.com.br/taxa-selic. Acesso em abril de 2020.

CORONADO, Osmar. Contabilidade gerencial básica. São Paulo: Saraiva, 2006.

COUTINHO, Giovanni. Selic: entenda como ela afeta a economia o consumo e o desemprego. Disponível em: https://dinheirama.com/selic-entenda-como-ela-afeta-aeconomia-o-consumo-e-o-desemprego. Acesso em julho de 2020.

EQUIPE ANDRE BONA, 11 Principais indicadores econômicos que você precisa conhecer. Disponível em: https://andrebona.com.br/11-principais-indicadores-economicosque-voce-precisa-conhecer. Acesso em agosto de 2020.

DURAN J. M, “A qualidade desde o projeto”, Thomson, 1992.

HERNANDES, Carlos Alberto.; CRUZ, Cláudio Silva da.; FALCÃO, Sérgio Dagnino. Combinando o Balanced Scorecard com a Gestão do Conhecimento.

Caderno de Pesquisas em Administração. São Paulo, vol. 01, n. 12. 2000. Disponível em: $<$ http://sistemas.aids.gov.br/incentivo/Biblioteca/Gestao_governanca/bsc_e _gestao_do_conhecimento.pdf>. Acesso em novembro de 2020.

LOGULLO, Flavio. Como a taxa de SELIC influencia sua empresa. Disponível em: https://controlefinanceiro.granatum.com.br/dicas/como-a-taxa-selic-influencia-suaempresa. Acesso: 2020.

LUCAS, Douglas Ribeiro; LUCAS, Denilson da Silva. Capital Intelectual: Conhecimento, Habilidade e Competências que Geram Receitas. Revista Mineira de Contabilidade. Minas Gerais, 2010, vol. 2, n. 38. Disponível em: <http://revista.crcmg.org.br. Acesso em: 21 Nov/2017. 
MARION, José Carlos. Análise das Demonstrações Contábeis: Contabilidade Empresarial. 7. ed. São Paulo: Atlas, 2012.

NONAKA, Ikujiro; TAKEUCHI, Hirotaka. Criação de conhecimento na empresa. Rio de Janeiro: Elsevier, 1997.

SALVALÁGIO, Alessandra Vieira de Souza. Analise e evolução da taxa selic meta em relação à taxa selic efetiva e seus reflexos sobre a dívida pública interna. Florianópolis, 2006.

SILVA, Tathiane. Você sabia que a taxa selic pode influenciar seu emprego? Abril/2016. Disponível em: https://administradores.com.br/artigos/voce-sabia-que-a-taxa-selic-podeinfluenciar-o-seu-emprego. Acesso em maio de 2020.

SOARES, C. S.; MACHADO, T. A.; SCHUMACHER, L. I. Aplicação de modelos de previsão de insolvência em empresa com situação de risco. Contabilidade e Informação, ljuí, n. 33, p. 31-41, jul./dez. 2010.

TERRA, José Claudio Cyrineu. Gestão do conhecimento: o grande desafio empresarial. São Paulo: Negócios, 2000.

WOLFFENBUTTE, Andréa 2005. Ano 2. Edição 7 - 1/2/2005 Disponível em: https://www.ipea.gov.br/desafios/index. Acesso em maio de 2020. 